\title{
Children with Cochlear Implants: Educational Placement and School Adjustment
}

\section{Jiaojiao Wu}

\begin{abstract}
To investigate the educational placement of children with cochlear implants and to study the adaptation level of these children and relevant influencing factors. Twenty children with cochlear implants were randomly selected and their parents and teachers were interviewed by telephone. The educational placement situation and the influencing factors on the adaptability of children with cochlear implants were studied through archival analysis, field observation and recording and in-depth interview. The child characteristics, acceptance of schools and teachers, family expectation, parents' communication had significant effects on the educational placement of children with cochlear implants. Results also indicated various sources of influence on school adjustment of these children after moving to educational placement, associated with the child, with the placements, with the families, and with other aspects. The educational placement shall be provided based on the characteristics of children and on the premise of meeting the unique educational needs of children, thus further providing the educational support for children with cochlear implants.
\end{abstract}

Key words: Cochlear implants, educational placement, school adjustment, influencing factors 


\section{Introduction}

Chinese domestic cochlear products came to market in 2011, which means that more people in need can offer cochlear implants by themselves or their families in China. Loosening cochlear indications in recent years, number of cochlear implants increased annually (Liu Jianju et al., 2012), more and more children implanted younger. It is blindingly obvious for all to see a large number of children with cochlear implants will face problem of educational placement. Though a variety of recent domestic studies have done in domains of cochlear effect, speech perception and language development, academic achievement etc., studies of educational placement are relatively rare.

Some foreign studies (e. g., Svirsky et al., 2004; Connor, 2006; Marschark et al., 2007) have shown that children with cochlear implants have demonstrated benefits to hearing, language, and speech from implants, leading to assumptions that early implantation and longer periods of implant should be associated with higher reading and academic achievement. Though studies by Archbold (Archbold et al., 2002) and Fortnum (Fortnum et al., 2002) confirmed the effect of cochlear implantation on education setting in favor of mainstream placements, noting that the shift in placement roughly equates the pupils with cochlear implants with severely deaf pupils of the same age, more school-aged deaf pupils with cochlear implants moved in the inverse direction over time (see Thoutenhoofd, 2006; Marschark et al., 2007). This article focuses on the implementation of the educational placement and school adjustment of children with cochlear implants. Considerations of methodological shortcomings in existing research as well as theoretical and practical questions yet to be addressed provide direction for future research.

\section{Methodology}

This study utilized data from multiple sources to gain a panoramic view of implementation of educational placement of children with cochlear implants. Telephone survey data were augmented by archival analysis of children and interviews of parents and teachers. A telephone survey protocol was developed to know (1) the impetus for the educational placement; (2) the process of their educational placement, including difficulties they encountered; and (3) whether a particular child had placement changes. The influencing factors on the adaptability of children with cochlear implants after moving to placements were studied through field observation and in-depth interview. During the in-depth interview, participants were asked to respond to a series of openended questions to describe children's school adjustment in their settings.

Twenty children with cochlear implants were randomly selected within Chengdu city, Sichuan province, China. 
Table 1

Child participant demographics $(N=20)$

\begin{tabular}{|c|c|c|c|c|c|}
\hline No. & Genders & Age now & $\begin{array}{c}\text { Age of } \\
\text { implantation }\end{array}$ & $\begin{array}{c}\text { Hearing } \\
\text { status } \\
\text { now (dB) }\end{array}$ & Placements \\
\hline 1 & female & $1 / 4$ & $2 / 1$ & 25 & public kindergarten \\
\hline 2 & male & $2 / 4$ & $3 / 1$ & 20 & public kindergarten \\
\hline 3 & male & $7 / 4$ & $6 / 2$ & 15 & public kindergarten \\
\hline 4 & male & $9 / 4$ & $0 / 2$ & 20 & private kindergarten \\
\hline 5 & male & $6 / 2$ & $5 / 5$ & 16 & public kindergarten \\
\hline 6 & $5 / 5$ & $8 / 5$ & $2 / 1$ & 70 & kindergarten in special school \\
\hline 7 & male & $11 / 5$ & $0 / 3$ & 24 & public kindergarten \\
\hline 8 & male & $3 / 7$ & $3 / 3$ & 35 & moving to special school \\
\hline 9 & female & $2 / 8$ & $2 / 3$ & 25 & regular school \\
\hline 10 & female & $4 / 8$ & $4 / 3$ & 50 & special school \\
\hline 11 & female & $1 / 9$ & $1 / 4$ & 65 & special school \\
\hline 12 & male & $9 / 9$ & $9 / 5$ & 50 & special school \\
\hline 13 & female & $10 / 9$ & $10 / 4$ & 20 & regular school \\
\hline 14 & male & $3 / 10$ & $2 / 5$ & 25 & special school \\
\hline 15 & male & $1 / 11$ & $1 / 6$ & 20 & regular school \\
\hline 16 & female & $5 / 11$ & $5 / 6$ & 35 & moving to special school \\
\hline 17 & female & $6 / 11$ & $6 / 6$ & 14 & regular school \\
\hline 18 & male & $11 / 11$ & $9 / 6$ & 25 & special school \\
\hline 19 & female & $5 / 16$ & $1 / 8$ & 46 & moving to special school \\
\hline 20 & male & $9 / 17$ & $3 / 8$ & 52 & moving to special school \\
\hline
\end{tabular}

Note: Data were collected in October, 2012. Special school here means school for the deaf

\section{Results}

\subsection{Educational placement}

Twenty participants were placed in four different settings (see Figure 1), including 1 in the kindergarten affiliated to special school and 9 in special school, 6 in public kindergarten for hearing students, and 4 in regular schools. In total, 35 percent of children (5 years to 7 years old) are accepting preschool education; 65 percent of children are accepting beyond preschool education, including 11 children ( 8 years to 13 years old) 
placed in primary school and 2 children (16 years to 17 years old) in the same high school for special needs.

Figure 1

Types of educational placements

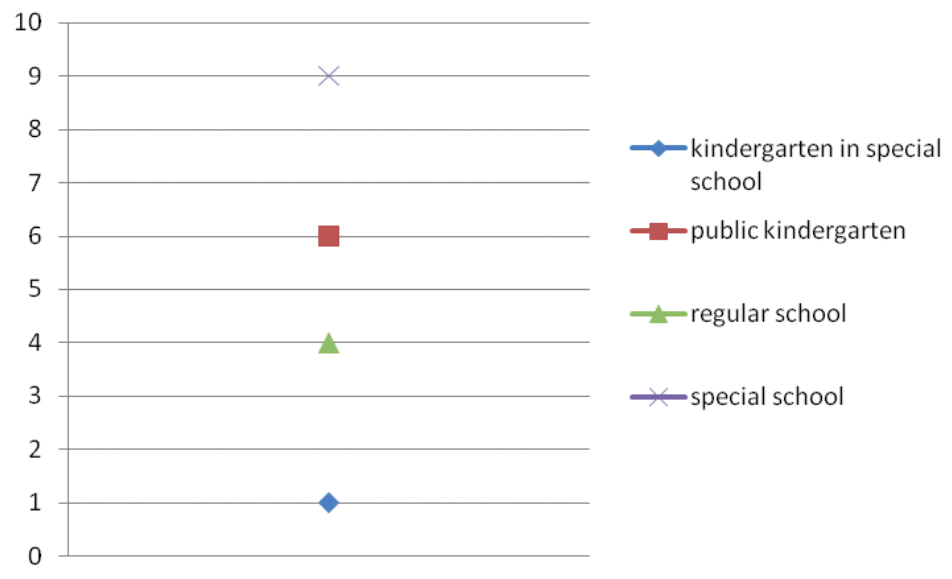

\subsection{Factors that may affect educational placements}

Table 2 indicates that individual characteristics are the main reasons for choosing types of educational placements for children with cochlear implants, including their hearing status, cochlear using level, mixed additional disabilities, personal experience as well as self-concept. When Luo chose junior high school, her experience in regular school came to her mind: the setting becomes more competitive, materials are more difficult, and expectations are higher. Her mom respected her decision and Luo finally moved to special school.

Look at the frequency given in descending order and hence the rate of answers to each coding items under every dimension is reduced gradually. Two other domains of influencing factors are closely related with family and educational placement itself. It was found that parents tend to choose regular schools and only use spoken language regardless of cochlear effect. What an important observation also suggests is that, for a number of children, communication varies at home, where signed communication model appears to be used much less. In fact, decision on communication influences a child's communication opportunities. 
Table 2

Factors that may affect educational placements

\begin{tabular}{|l|l|c|c|}
\hline Dimension & Coding & Frequency & Percent \\
\hline child characteristics & hearing status & 17 & 85 \\
\hline & cochlear using level & 14 & 70 \\
\hline & mixed additional disabilities & 12 & 60 \\
\hline & personal experience & 5 & 25 \\
\hline & self-concept & 4 & 20 \\
\hline families & total & 52 & 80 \\
\hline & family expectation & 16 & 40 \\
\hline & communication & 8 & 15 \\
\hline & parents' hearing status & 3 & 65 \\
\hline placements & total & 27 & 35 \\
\hline & school acceptance & 13 & \\
\hline & teachers' acceptance & 7 & 20 \\
\hline
\end{tabular}

\subsection{School adjustment}

After moving to placements, the school adjustment of children is different from each other according to implementation and assessment practices by observation and teacher interviews. All items and indicators intact are organized into four subscales: academic attainment, peer relationships, communication, and attitude towards learning.

Another notable finding in the data is that the adaptation level (see Figure 2) of the cochlear implants in special school is higher than other two types of placements. 6 children were reported to adapt themselves to special school very well. Only one child who newly moved to the special school was reported not well. The other 3 felt good in special school, reaching the average level. Just the reverse, only one child was reported very well in regular school, but two were reported not very well and were planning migration. 
Figure 2

Children's adaption level in placement

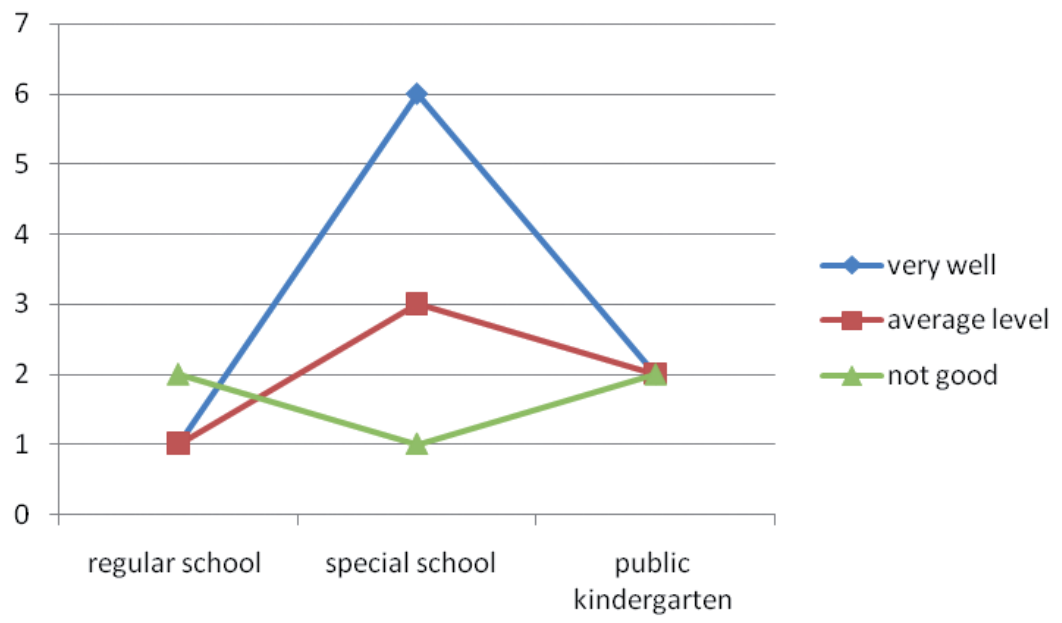

\subsection{Factors that may affect children's school adjustment}

Children's school adjustment in educational placement appears to depend on a variety of factors. Table 3 indicates a four-dimensional framework of factors: child characteristics, placements, family factors and the others. Some characteristics mark children off from the others. The total of eleven coding items are integrated: hearing status, communication, language development, study pressure, academic attainment, peer relationship, learning quality, emotion expression, intelligence, personality, and self-efficacy.

Looking at the frequency given in descending order, social support from teachers and peers, and professionals has significant regression effect on children's school adjustment whatever in any kind of placements they are. Families and whether the child accepted early childhood education and even different lengths of time moving to placement influence the school adjustment, usually, children encounter more problems at the beginning. To get enough information in real time that would allow for interaction during the class, however, children's generally educational needs such as the support of a note taker or real-time captioning option are insufficient.

Parenting a child with cochlear implants is not easy, some parents face challenges to meet the complex needs of children with cochlear implants. Likewise, family expectation influence family involvement in habilitation process, the same as the family functioning, which also influences how families involve in children's studies. 
Table 3

OFactors that may affect children's school adjustment

\begin{tabular}{|c|c|c|c|}
\hline Dimension & Coding & Frequency & Percent \\
\hline \multirow[t]{12}{*}{ child characteristics } & hearing status & 19 & 95 \\
\hline & communication & 17 & 85 \\
\hline & language development & 12 & 60 \\
\hline & study pressure & 12 & 60 \\
\hline & academic attainment & 11 & 55 \\
\hline & peer relationship & 9 & 45 \\
\hline & learning quality & 7 & 35 \\
\hline & emotion expression & 6 & 30 \\
\hline & intelligence & 6 & 30 \\
\hline & personality & 5 & 25 \\
\hline & self-efficacy & 4 & 20 \\
\hline & total & 108 & \\
\hline \multirow[t]{8}{*}{ placements } & oral/sign language teaching & 15 & 75 \\
\hline & class size & 13 & 65 \\
\hline & teachers' acceptance & 9 & 45 \\
\hline & teachers' special education skills & 7 & 35 \\
\hline & arrangements of seats & 8 & 40 \\
\hline & courses program & 6 & 30 \\
\hline & educational environment & 5 & 25 \\
\hline & total & total & \\
\hline \multirow[t]{5}{*}{ families } & communication & 18 & 90 \\
\hline & family functioning & 15 & 75 \\
\hline & parental stress & 13 & 65 \\
\hline & family expectation & 11 & 55 \\
\hline & total & 57 & \\
\hline \multirow[t]{4}{*}{ others } & early childhood education & 14 & 70 \\
\hline & social support for professionals & 12 & 60 \\
\hline & length of time moving to placement & 6 & 30 \\
\hline & total & 32 & \\
\hline
\end{tabular}

\section{Discussion}

\section{Changes in placement}

The children in this study are predominantly based in special schools, a total of four children had migration between different placements, all of them moved from regular 
schools to special schools, without exception. One child migrated on second grade, one moved on third grade, and another two had migration after their first year in high school. It must also be borne in mind that the changes in placement that were counted imply different kinds of change for children in different situations.

Huge study pressure is the key reason for causing their migration. It's really hard for them to fulfil academic requirements for school or teachers. And then, as time goes on, lower self-efficacy and acceptance level by peers happened, and finally they gradually grew up lacking interest in learning.

As for children who had good school adjustment, teachers reported their cognition developed well, they're outgoing and usually have many good friends in school. Parents have great role in child's psychological development and involves actively in studies to cultivate their learning quality.

\section{Difference between preschool and primary or secondary school placements}

In sum, children's adaption level in preschool is the highest in placements, namely, children's school adjustment is the best in kindergarten other than in primary or secondary school.

In kindergarten, most of the time children learn by playing games, however, it's totally different when they start the primary school, their schoolbags are getting heavier, and courses are more difficult. They have to face challenges of university entrance examination or thinking about job-hunting in senior high school.

\section{The child and family have significant influences both on placement and school adjustment}

The child characteristics strongly influence educational placement, there are a total of 52 frequencies, all coding are (see Table 2): hearing status, cochlear using level, mixed additional disabilities, personal experience of placements, and self-concept. For the family, family expectation, parents' hearing status, and communication are influencing factors. Table 3 indicates child characteristics that may affect children's school adjustment, a total of eleven coding items are integrated: hearing status, communication, language development, study pressure, academic attainment, peer relationship, learning quality, emotion expression, intelligence, personality, and self-efficacy. Also, family expectation, parental stress, communication, and family functioning have significant influences on school adjustment.

\section{Insufficient support from regular schools}

What matters in education is not how well a child can hear but whether a child has unimpeded access to the social interactive process of teaching and learning. In contrast with special school for deaf students, a hypothesis exists in regular school is that only spoken language access to education. The best approach might be a bilingual strategy 
that be provided for children with cochlear implants. If we truly want these children to succeed, we must confront environmental and methodological barriers to education and to appropriate educational assessment (Marschark et al., 2006).

School acceptance remains to be further implemented. Where there is indeed progression toward bilingual approaches to teaching and learning. Teachers in regular school whose special education skills should be improved by making the fullest use of special education center and resources bases.

\section{Conclusions}

The study was mainly based on interview and observation, a notable finding in the data is that seven kindergarten children were implanted at younger age (1.7 years on average) than the primary and secondary school children (5.1 years on average). Nevertheless, age at implantation has been seen as a significant predictor of later placements (Archbold et al., 1998). There is need to do more follow-up studies of those kindergarten children.

The educational placement shall be provided based on the characteristics of children and on the premise of meeting the unique educational needs of children, thus further providing the educational support for children with cochlear implants. Parents, educators, and professionals must work together to assist children in achieving their goals. Educational strategies for children with cochlear implants must take into consideration that these children will need direct instruction to develop communication competence.

\section{References}

Ertmer, D. J. \& Mellon, J. A. (February 01, 2001). Beginning to Talk at 20 Months: Early Vocal Development in a Young Cochlear Implant Recipient. Journal of Speech, Language, and Hearing Research, 44, 1, 192-206.

Thoutenhoofd, E. (November 23, 2005). Cochlear Implanted Pupils in Scottish Schools: 4-Year School Attainment Data (2000-2004). Journal of Deaf Studies and Deaf Education, 11, 2, 171-188.

Liu Jianju, Sun Xibin. (2012). A Review of Rehabilitation Effect Assessment. Disability research 2, 11. Marschark, M., Rhoten, C., \& Fabich, M. (January 01, 2007). Effects of Cochlear Implants on Children's Reading and Academic Achievement. Journal of Deaf Studies and Deaf Education, 12, 3, 269-82. Hintermair, M. (2006). Parental Resources, Parental Stress, and Social Motional Development of Deaf and Hard of Hearing Children. Journal of Deaf Studies and Deaf Education. 11, 4, 493-513. Hyde, M., \& Power, D. (March 08, 2007). Some Ethical Dimensions of Cochlear Implantation for Deaf Children and Their Families. Journal of Deaf Studies and Deaf Education, 11, 1, 102-111. 
Nikolopoulos, T. (February 01, 2004). Predicting Speech Perception Outcomes Following Cochlear Implantation Using Nottingham Children's Implant Profile (NChIP). International Journal of Pediatric Otorhinolaryngology, 68, 2, 137-141.

Bat-Chava, Y., \& Deignan, E. (September 06, 2001). Peer Relationships of Children with Cochlear Implants. Journal of Deaf Studies and Deaf Education, 6, 3, 186-99.

\section{Contact:}

Mgr. Jiaojiao Wu, Ph.D.

Faculty of Education

Palacký University Olomouc

Žižkovo nám. 5

77140 Olomouc, CZ

E-mail: joannahhwu@gmail.com 